Pesq. Vet. Bras. 35(8):725-733, agosto 2015 DOI:10.1590/S0100-736X2015000800004

\title{
Aspectos patológicos e microbiológicos das doenças respiratórias em suínos de terminação no Brasil ${ }^{1}$
}

\author{
Marcos A.Z. Morés², João X. Oliveira Filho ${ }^{3}$, Raquel Rebelatto², Cátia S. Klein², David \\ E.N. Barcellos ${ }^{3}$, Arlei Coldebella ${ }^{2}$ e Nelson Morés ${ }^{2 *}$
}

\begin{abstract}
Morés M.A.Z., Oliveira Filho J.X., Rebelatto R., Klein C.S., Barcellos D.E.N., Coldebella A. \& Morés N. 2015. [Pathological and microbiological aspects of respiratory disease in fattening pigs in Brazil.] Aspectos patológicos e microbiológicos das doenças respiratórias em suínos de terminação no Brasil. Pesquisa Veterinária Brasileira 35(8):725-733. Embrapa Suínos e Aves, Empresa Brasileira de Pesquisa Agropecuária, BR-153 Km 110, Caixa Postal 21, Distrito de Tamanduá, Concórdia, SC 89700-000, Brazil. E-mail: nelson.mores@embrapa.br

For pathological and microbiological evaluation of porcine respiratory disease in fattening pigs, seventy five animals showing respiratory distress, fever and/or cough were analyzed. These pigs were necropsied and samples were collected for histological and microbiological analysis. Bacterial isolation procedures were performed aiming to detect major swine bacterial respiratory pathogens. Also, PCR for Mycoplasma hyorhinis, and immunohistochemistry for Influenza A, porcine circovirus type 2, and Mycoplasma hyopneumoniae were carried out. Mycoplasma hyopneumoniae and Pasteurella multocida type A were the most prevalent infectious agents. The antimicrobial sensitivity of 24 samples of P. multocida type A was evaluated by minimum inhibitory concentration tests and all these samples were sensitive to doxycycline, tilmicosin and enrofloxacin. Suppurative bronchopneumonia and pleuritis were main respiratory lesions found. When P. multocida type A was present, the extension of lung lesions was increased. In $58 \%$ of the samples more than one infectious agent was identified, suggesting a high prevalence of infectious agents associations in porcine respiratory disease in Brazil.
\end{abstract}

INDEX TERMS: Swine, pneumonia, Pasteurella multocida, Mycoplasma hyopneumoniae.

RESUMO.- Para avaliação dos aspectos patológicos e microbiológicos de casos clínicos de doenças respiratórias em suínos de terminação foram analisados 75 suínos doentes oriundos de 36 lotes. Suínos que apresentavam sinais clínicos respiratórios evidentes foram necropsiados para avaliação macroscópica e colheita de amostras para análise histopatológica e microbiológica. Foram realizados testes de isolamento bacteriano para as principais bactérias do sistema respiratório dos suínos, PCR para Mycoplasma hyorhinis, imuno-histoquímica para

\footnotetext{
${ }^{1}$ Recebido em 3 de dezembro de 2014.

Aceito para publicação em 10 de junho de 2015.

${ }^{2}$ Embrapa Suínos e Aves, Rodovia BR-153 Km 110, Cx. Postal 21, Distrito de Tamanduá, Concórdia, SC 89700-000, Brasil. *Autor para correspondência: nelson.mores@embrapa.br

${ }^{3}$ Departamento de Medicina Animal, Universidade Federal do Rio Grande do Sul (UFRGS), Agronomia, Av. Bento Gonçalves 9090, Porto Alegre, RS 91540-000, Brasil.
}

Influenza A, Circovirus suíno tipo 2 e Mycoplasma hyopneumoniae. A sensibilidade antimicrobiana de 24 amostras de Pasteurella multocida tipo A foi avaliada por testes de concentração inibitória mínima para os principais antimicrobianos utilizados em suinocultura. Mycoplasma hyopneumoniae e Pasteurella multocida tipo A foram os agentes infecciosos mais prevalentes. Broncopneumonia supurativa e pleurite foram as principais lesões respiratórias encontradas. Pasteurella multocida tipo A, quando presente, aumentou a extensão das lesões pulmonares. Todas as amostras de Pasteurella multocida testadas foram sensíveis aos antimicrobianos Doxiciclina, Enrofloxacina e Tilmicosina. Em 58\% das amostras foi identificado mais de um agente infeccioso, evidenciando a alta prevalência da associação de agentes nas doenças respiratórias de suínos em terminação.

TERMOS DE INDEXAÇ̃̃O: Suínos, pneumonias, Pasteurella multocida, Mycoplasma hyopneumoniae. 


\section{INTRODUÇÃO}

As doenças infecciosas causam grandes prejuízos à cadeia produtiva de suínos em todos os países com produção intensiva, sendo as respiratórias as mais prevalentes. No Brasil, as doenças infecciosas respiratórias se tornaram mais importantes devido às características dos atuais sistemas de produção, nos quais os animais são criados confinados em altas densidades, além das misturas de animais de várias origens nas diferentes fases da produção. Estes fatores, além de causarem estresse aos animais, facilitam a disseminação dos agentes agravando os problemas respiratórios (Fraile et al. 2010, Opriessnig et al. 2011).

Os principais agentes infecciosos respiratórios dos suínos são enzoóticos na maioria das granjas, sendo que alguns deles fazem parte da microbiota normal do trato respiratório. Porém, a ocorrência de doença é variável, sendo influenciada pela presença, em maior ou menor grau, dos fatores de risco ambientais e de manejo que predispõem os animais às infecções (Fraile et al. 2010, Opriessnig et al. 2011).

Estes fatores, associados às características dos agentes infecciosos, fazem com que, na maioria das vezes, os quadros clínicos respiratórios dos suínos nas fases de crescimento e terminação, sejam causados pela associação de dois ou mais microrganismos (Hansen et al. 2010, Opriessnig et al. 2011). Devido à interação de vários agentes infecciosos com os fatores de risco, o termo "complexo das doenças respiratórias dos suínos" (CDRS) é empregado com frequência para referenciar estes quadros clínicos (Thacker 2006, Hansen et al. 2010).

A associação de agentes infecciosos torna mais difícil o controle destas infecções. Portanto, o diagnóstico correto dos agentes envolvidos é essencial e depende de uma avaliação patológica e etiológica adequada dos quadros clínicos.

O objetivo desse trabalho foi identificar as características patológicas e os principais agentes infecciosos envolvidos nos quadros clínicos respiratórios em suínos de terminação no Brasil, assim como avaliar a sensibilidade antimicrobiana do principal agente bacteriano isolado.

\section{MATERIAL E MÉTODOS}

\section{Amostras}

Entre os anos de 2011 e 2012 foram avaliados 36 lotes comerciais de suínos com idade entre 100 e 180 dias de vida, os quais apresentavam quadro clínico grave de doença respiratória. Visando abranger as principais regiões produtoras do Brasil, incluíram-se lotes localizados nos Estados do Mato Grosso (n=09), Mato Grosso do Sul (n=05), Paraná ( $\mathrm{n}=07)$, Rio Grande do Sul $(\mathrm{n}=10)$ e Santa Catarina (n=05). Em cada lote foi realizada avaliação clínica dos animais, incluindo tosse, espirros, dispneia e temperatura retal de animais com dispneia. Com base nessa avaliação, de cada lote foram selecionados de 1 a 3 suínos (totalizando 75 suínos) que apresentavam sinais clínicos respiratórios acentuados, principalmente dispneia e hipertermia (temperatura retal acima de $40^{\circ} \mathrm{C}$ ) e eventualmente tosse. Esses animais foram submetidos à eutanásia por eletrocussão e necropsiados nas próprias granjas para avaliação patológica e colheita de amostras para análises laboratoriais. Este trabalho foi aprovado pelo Comitê de Ética em Experimentação Animal (CEUA/CNPSA) (Protocolo 005/2010). Os trabalhos de avaliação clínica, escolha dos animais para ne- cropsia e necropsia foram realizados, em todos os lotes, por dois veterinários com experiência em clínica e patologia de suínos.

Para isolamento bacteriano foram colhidas amostras do pulmão lesado e exsudatos de pleura e pericárdio, quando presentes. Estas amostras foram acondicionadas em sacos plásticos estéreis, refrigeradas imediatamente após a colheita e processadas em até 24 horas. Todas as amostras foram processadas pelo mesmo técnico, em três laboratórios diferentes, equipados com estrutura necessária semelhante.

Para análise histopatológica e de imuno-histoquímica foram colhidas amostras de lesões pulmonares, pericárdio, fígado, rim, coração, traqueia e linfonodos mediastínicos. Os tecidos foram imediatamente fixados em formalina $10 \%$ tamponada e mantidas neste fixador por 48 horas para posterior processamento histológico.

\section{Questionário epidemiológico}

Durante as visitas às granjas, foi preenchido um questionário com as informações sobre o sistema de criação e uso de antibióticos e vacinas. As informações foram fornecidas pelos responsáveis pelos animais, proprietário ou empresa integradora.

\section{Patologia}

Macroscopia. As lesões observadas nas necropsias foram descritas em formulário específico. As lesões de consolidação pulmonar foram graduadas quanto à extensão utilizando-se a média de escores de cada lobo em relação à área total do pulmão, como descrito por Piffer \& Brito (1991). Quanto à distribuição, as lesões de consolidação pulmonar foram classificadas em crânio-ventral, focal ou multifocal e difusa. As lesões na pleura foram classificadas quanto à extensão em: grau 1 com até $33 \%$ de envolvimento; grau 2 entre 33 e $66 \%$ e grau $3>66 \%$ de área afetada. Outras lesões foram anotadas como presentes ou ausentes.

Histopatologia. Após a fixação, os tecidos foram desidratados, clarificados, embebidos em parafina, seccionados com 2-5 $\mu \mathrm{m}$ de espessura e corados pela hematoxilina e eosina (HE), conforme procedimentos de rotina. Na análise histopatológica foram avaliadas todas as estruturas do tecido pulmonar (brônquios, bronquíolos, alvéolos e pleura) (Hansen et al. 2010). 0 infiltrado inflamatório no exsudato alveolar foi avaliado para caracterizar as lesões como crônicas, subagudas e agudas (Hansen 2010). A hiperplasia do tecido linfoide associado aos brônquios foi classificada como presente ou ausente.

Imuno-histoquímica (IHQ). Secções selecionadas de lesões pulmonares de todas as amostras foram montadas em lâminas tratadas com poly-L-lisine e processadas para detecção de antígenos de Mycoplasma hyopneumoniae (Mhyo), Circovírus suíno tipo 2 (PCV2) e vírus Influenza A. A pesquisa de PCV2 foi realizada também em amostras de linfonodos mediastínicos. Para todos os agentes foi utilizado o método biotina-estreptavidina-peroxidase, cromógeno 3-Amino-9-Ethylcarbazol (AEC) e contra-coloração com hematoxilina de Mayer.

Para detecção do Mhyo foi utilizado um anticorpo recombinante policlonal monoespecífico contra proteína lactato-desidrogenase - p36 (Castro et al. 2009). 0 procedimento da IHC foi padronizado pelo método estreptavidina-biotina-peroxidase, com kit comercial (Kit LSAB ${ }^{\circledR}+$ System - HRP - DakoCytomation ${ }^{\circledR}$ ). A recuperação antigênica foi feita com a imersão das lâminas em tampão citrato (pH 6,0) e tratamento pelo calor em um forno de micro-ondas doméstico por cinco minutos, na potência de $700 \mathrm{~W}$. Posteriormente, foi realizada digestão enzimática, utilizando-se pepsina $0,04 \%$ diluída em ácido clorídrico $0,01 \mathrm{~N}(\mathrm{pH} 7,8)$ durante 10 minutos a $37^{\circ} \mathrm{C}$. As secções de tecido foram marcadas com o anticorpo primário (anti-p36) por 2 horas a $37^{\circ} \mathrm{C}$. A coloração 
final foi realizada com a solução AEC por cinco minutos a $37^{\circ} \mathrm{C}$ e a contra coloração com hematoxilina de Mayer por dois minutos. Nos testes para detecção de PCV2 e Influenza A, foram utilizadas as metodologias descritas na literatura (Ciacci-Zanella et al. 2006, Vincent et al. 1997).

\section{Microbiologia}

Isolamento bacteriano. Lesões pulmonares, suabes e exsudatos dos animais necropsiados foram semeados em placas de ágar sangue e ágar MacConkey (Difcoä) e incubados a $37^{\circ} \mathrm{C}$ por 18-24 horas em atmosfera de aerobiose. Colônia Staphylococcus aureus nutris de nicotinamida adenina dinucleotídeo (NAD) foi adicionada nas placas de ágar sangue e estas foram incubadas em microaerofilia a $37^{\circ} \mathrm{C}$ por $24-48 \mathrm{~h}$. A caracterização bioquímica das colônias foi realizada de acordo com Quinn et al. (2011) para a identificação das bactérias.

PCR para detecção de Mycoplasma hyorhinis (Mhyr). Devido à indisponibilidade de tecido, somente 59 das 75 amostras de pulmão foram processadas para detecção de Mhyr. O DNA foi extraído utilizando-se o Kit comercial DNeasy ${ }^{\circledR}$ Blood \& Tissue $\left(\right.$ Qiagen $\left.{ }^{\mathrm{TM}}\right)$. A PCR foi realizada conforme descrito por Stakenborg et al. (2006), utilizando-se apenas o primer para detecção de Mhyr (GenBank acesso no M24658) e o primer reverse (região conservada do gene $16 \mathrm{~S}$ rRNA), resultando em uma amplificação de $1129 \mathrm{pb}$.

Teste de concentração inibitória mínima (CIM). Pasteurella multocida tipo A (PMA) foi o único agente bacteriano isolado com frequência significativa, sendo portanto o único avaliado pela técnica de CIM. Das 43 amostras de P. multocida tipo A isoladas, foram selecionadas 24, buscando-se distribuição igualitária por Estado, para a realização deste teste. Para isso utilizou-se a técnica de microdiluição em caldo, conforme estabelecido pelo Clinical and Laboratory Standards Institute-CLSI (CLSI, 2005). Como padrões de sensibilidade e resistência, foram utilizadas amostras de referência preconizadas no CLSI: Escherichia coli ATCC 25922 e Staphylococcus aureus ATCC 29213. Foram testadas 12 drogas: amoxicilina (AMO), ceftiofur (CTF), clortetraciclina (CTC), doxicilina (DOX), enrofloxacina (ENO), espectinomicina (EPT), florfenicol (FFN), norfloxacina (NOR), oxitetraciclina (OTC), tiamulina (TF) e tilmicosina (TYL), e quatro associações: AMO/TF (na proporção 2,0:1,2), AMO/TYL (2,0:1,0), DOX/TF $(2,0: 1,2)$ e LIN/EPT $(5,0: 1,0)$. O ponto de corte da CIM para AMO e CTC foi estabelecido conforme Tang et al. (2009), pois, para essas drogas, não há critérios descritos para P. multocida no CLSI (CLSI, 2005). Para as associações de antibióticos foram calculados os valores do índice de fração inibitória (ICIF) conforme Garcia et al. (2010), e a interpretação do ICIF foi realizada de acordo com Eucast (2000), sendo considerado efeito sinérgico (ICIF menor ou igual a 0,5 ), aditivo (ICIF maior que 0,5 e menor ou igual a 1 ), indiferente (ICIF maior que 1 e menor ou igual a 4) e antagônico (ICIF maior que 4).

\section{Análise estatística}

O teste Qui-quadrado foi utilizado para avaliar algumas associações com variáveis microbiológicas, de imuno-histoquímica e alterações patológicas. $\mathrm{O}$ teste $\mathrm{T}$ foi utilizado para avaliar o efeito do isolamento bacteriano para P. multocida tipo A sobre a extensão das lesões pulmonares. 0 software estatístico adotado foi o SAS versão 9.2 (2008).

\section{RESULTADOS \\ Questionário epidemiológico}

Quanto ao sistema de produção, 58 (77\%) suínos amostrados eram provenientes de lotes de terminações de sistemas segregados e 17 (23\%) de granjas de ciclo completo
Quadro 1. Utilização de vacinas em 26 lotes

\begin{tabular}{|c|c|c|}
\hline Vacina & Tipo de Vacina & $\mathrm{N}^{\mathrm{a}}(\%)$ \\
\hline PCV2 & Comercial $^{\mathrm{b}}$ & $25(96,1)$ \\
\hline Mycoplasma hyopneumoniae & Comercial & $24(92,3)$ \\
\hline Actinobacillus pleuropneumoniae & Autógenac & $4(15,4)$ \\
\hline Actinobacillus pleuropneumoniae & Comercial & $9(34,6)$ \\
\hline Haemophilus parasuis & Comercial & $5(19,2)$ \\
\hline Pasteurella multocida & Autógena & $2(7,7)$ \\
\hline Pasteurella multocida & Comercial & $9(34,6)$ \\
\hline Streptococcus suis & Autógena & $1(3,8)$ \\
\hline
\end{tabular}

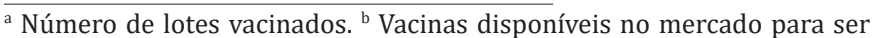
utilizada por qualquer granja. ${ }^{c}$ Vacina produzida com agente isolado da própria granja.

Quadro 2. Antibióticos utilizados nos programas preventivos durante as fases de crescimento e terminação em 26 lotes

\begin{tabular}{lcc}
\hline Antibiótico & $\mathrm{N}^{\mathrm{a}}(\%)$ & Dosagem $(\mathrm{ppm})$ \\
\hline Tiamulina & $16(61,5)$ & $40-200$ \\
Florfenicol & $13(50,0)$ & $40-100$ \\
Amoxilina & $9(34,6)$ & $200-300$ \\
Tilosina & $4(15,4)$ & 125 \\
Doxicilina & $4(15,4)$ & $120-500$ \\
Avilamicina & $2(7,7)$ & $40-60$ \\
Oxitetraciclina & $2(7,7)$ & 500 \\
Lincomicina & $1(3,8)$ & 150 \\
Norfloxacina & $1(3,8)$ & ni \\
Tilmicosina & $1(3,8)$ & 150
\end{tabular}

a Número de lotes que utilizaram o antibiótico; ni = não informado.

(nascimento - abate). 0 número de origens dos leitões das terminações do sistema segregado variou entre uma (48\%) e até 19 (52\%) origens.

Nos Quadros 1 e 2 estão os resultados de uso de vacinas e antibióticos nos lotes, respectivamente. Estas informações foram obtidas em 26 dos 36 lotes estudados.

As vacinas mais usadas nos lotes amostrados foram para PCV2 (96,1\%), seguido da vacina para Mycoplasma hyopneumoniae (Mhyo)(92,3\%), Actinobacillus pleuropneumoniae (App) (50,0\%) e Pasteurella multocida (42,3\%). Os antibióticos mais utilizados foram tiamulina $(61,5 \%)$, seguido pelo florfenicol (50,0\%) e Amoxilina (34,6\%).

No Quadro 3 são apresentados dados das análises de associação entre algumas variáveis relacionadas com os principais agentes infecciosos identificados nas amostras. Os lotes que utilizaram vacina autógena para $P$. multocida tiveram significativamente menos isolamentos de Pasteurella multocida tipo A (PMA). A utilização de vacina para Mhyo não teve associação com os resultados de imuno-histoquímica para este agente. Houve associação $(\mathrm{P}<0,01)$ entre a hiperplasia de BALT com a IHQ para o Mhyo.

\section{Sinais clínicos e alterações patológicas}

Dispneia e febre estavam presentes em 98,6\% dos animais amostrados. Tosse não foi avaliada individualmente por ser um sinal intermitente, porém em 100\% dos lotes havia animais com tosse. Nenhum dos lotes apresentou níveis significativos de espirros.

Consolidação pulmonar $(98,6 \%)$ e alterações na pleura (24\%) foram as lesões respiratórias mais encontradas nas necropsias. Quanto à extensão das áreas de consolidação pulmonar as amostras variaram entre 2\% e 60\% de área 
Quadro 3. Relação entre agentes infecciosos, utilização de vacinas e tipo de lesão

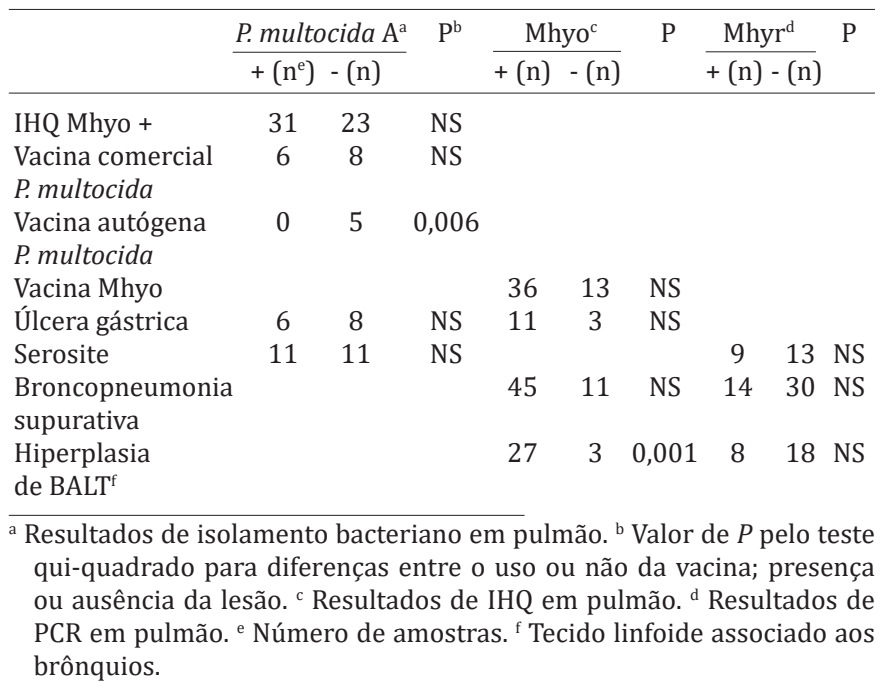

pulmonar afetada, com maior frequência $(25 \%$ das amostras) entre $20 \%$ e $30 \%$. As porcentagens das lesões macro e microscópicas observadas, correlacionadas com os agentes infecciosos pesquisados, são apresentadas nos Quadros $4 \mathrm{e}$ 5 , respectivamente. Todos os suínos necropsiados apresentavam comprometimento do aparelho respiratório, confirmando as observações clínicas.
Quanto à distribuição das lesões macroscópicas de consolidação no parênquima pulmonar, 73,6\% foram crânio-ventrais (Fig.1), 16,7\% multifocais (Fig.2) e 8,3\% difusas. A extensão das lesões na pleura foi: grau $1(9,7 \%)$, grau 2 $(4,2 \%)$ e grau $3(11,1 \%)$.

Em 33 amostras havia mais de um tipo de lesão respiratória no mesmo animal, consolidação pulmonar associada com aderências de pleura e pericárdio (Fig.3) em 21 amostras, consolidação pulmonar com pulmão não colabado (Fig.4) em 8 amostras, e consolidação pulmonar com nódulos pulmonares em 4 amostras.

$\mathrm{Na}$ histologia, as broncopneumonias foram classificadas como agudas, subagudas e crônicas em 1,3\%, 29,3\% e $46,7 \%$ dos casos, respectivamente. Lesões microscópicas agudas na pleura visceral, com exsudação fibrinossupurativa, foram observadas em $4 \%$ das amostras analisadas, enquanto lesões crônicas, com fibrose, ocorreram em 16\%, normalmente associadas com broncopneumonia. As principais lesões microscópicas encontradas no pulmão foram hiperplasia de BALT (90,7\%) (Fig.5), broncopneumonia supurativa $(77,3 \%)$ e pneumonia intersticial $(20 \%)$.

\section{Etiologia}

Na Figura 6 são apresentadas as porcentagens de positividade dos agentes infecciosos pesquisados, identificados isoladamente ou em associações. Dos 75 suínos analisados, em $44(58,8)$ foi identificado mais de um agente

Quadro 4. Frequência das principais lesões macroscópicas em suínos com quadro clínico respiratório e relação com os agentes infecciosos pesquisados

\begin{tabular}{|c|c|c|c|c|c|c|c|}
\hline \multirow[t]{2}{*}{ Lesão macroscópica } & \multirow[t]{2}{*}{$\mathrm{N}^{\mathrm{a}}$} & \multirow[t]{2}{*}{$\%$} & \multirow{2}{*}{$\begin{array}{c}\text { Isolamento } \\
\text { de } \mathrm{PmA}^{\mathrm{b}} \\
\%\end{array}$} & \multicolumn{3}{|c|}{ Imuno-histoquímica $^{\mathrm{b}}$} & \multirow{2}{*}{$\begin{array}{c}\mathrm{PCR}^{\mathrm{b}} \\
\text { Mhyr } \\
\%\end{array}$} \\
\hline & & & & $\begin{array}{c}\text { Mhyo } \\
\%\end{array}$ & $\begin{array}{c}\text { Influenza } \\
\%\end{array}$ & $\begin{array}{c}\text { PCV2 } \\
\%\end{array}$ & \\
\hline Consolidação pulmonar & $74 / 75$ & 98,6 & 53,3 & 69,3 & 2,7 & 4,0 & 25,3 \\
\hline Exsudato ou aderências na pleura visceral & $18 / 75$ & 24,0 & 72,2 & 83,3 & 0,0 & 0,0 & 33,3 \\
\hline Nódulo pulmonar & $6 / 75$ & 8,0 & 50,0 & 50,0 & 0,0 & 0,0 & 50,0 \\
\hline Espessamento e congestão na mucosa traqueal & $4 / 61$ & 6,6 & 75,0 & 75,0 & 0,0 & 0,0 & 25,0 \\
\hline Exsudato ou aderências no pericárdio & $11 / 75$ & 14,7 & 63,6 & 72,7 & 9,0 & 0,0 & 54,5 \\
\hline Exsudato ou aderências no peritônio & $6 / 56$ & 10,7 & 66,7 & 66,7 & 0,0 & 0,0 & 83,3 \\
\hline Úlcera gástrica & $14 / 55$ & 25,4 & 42,3 & 78,6 & 0,0 & 7,1 & 21,4 \\
\hline Pontos brancos no parênquima renal & $10 / 55$ & 18,2 & 60,0 & 60,0 & 0,0 & 10,0 & 30,0 \\
\hline
\end{tabular}

a Número de amostras com a lesão/número total de animais avaliados; o $\mathrm{N}$ é variável porque alguns tecidos não foram avaliados em todos os animais. ${ }^{\mathrm{b}}$ Percentual de amostras com a lesão e positivas para Pasteurella multocida (PmA), Mycoplasma hyopneumoniae (Mhyo), Mycoplasma hyorhinis (Mhyr) e Influenza A em amostras de pulmões e Circovírus suíno Tipo 2 (PCV2) em linfonodos mediastínicos.

Quadro 5. Frequência das principais lesões pulmonares microscópicas em 75 suínos com quadro clínico respiratório e relação com agentes infecciosos pesquisados

\begin{tabular}{|c|c|c|c|c|c|c|c|}
\hline \multirow[t]{2}{*}{ Lesão microscópica } & \multirow[t]{2}{*}{$\mathrm{N}$} & \multirow[t]{2}{*}{$\%$} & \multirow{2}{*}{$\begin{array}{c}\text { Isolamento } \\
\text { de } \mathrm{Pm}^{\mathrm{a}} \\
\% \\
\end{array}$} & \multicolumn{3}{|c|}{ Imuno-histoquímica $^{a}$} & \multirow{2}{*}{$\begin{array}{c}\text { PCR }^{\mathrm{a}} \\
\text { M.hyr } \\
\% \\
\end{array}$} \\
\hline & & & & $\begin{array}{c}\text { Mhyo } \\
\%\end{array}$ & $\begin{array}{c}\text { Influenza } \\
\%\end{array}$ & $\begin{array}{c}\text { PCV2 } \\
\%\end{array}$ & \\
\hline Broncopneumonia supurativa & 58 & 77,3 & 56,7 & 80,3 & 1,8 & 5,4 & 31,2 \\
\hline Pleuropneumonia fibrinosa, com ou sem necrose & 12 & 16,0 & 66,7 & 75,0 & 0,0 & 0,0 & 58,0 \\
\hline Hiperplasia de BALT & 68 & 90,7 & 57,3 & 76,5 & 0,0 & 2,9 & 32,7 \\
\hline Bronquite/bronquiolite necrosante & 3 & 4,0 & 0,0 & 33,3 & 66,7 & 0,0 & 33,3 \\
\hline Bronquite/bronquiolite epitelial proliferativa & 6 & 8,0 & 16,7 & 66,7 & 0,0 & 0,0 & 50,0 \\
\hline Pneumonia granulomatosa & 1 & 1,3 & 100,0 & 100,0 & 0,0 & 0,0 & - \\
\hline Pneumonia intersticial & 15 & 20,0 & 33,3 & 53,3 & 13,3 & 0,0 & 20,0 \\
\hline
\end{tabular}

${ }^{a}$ Percentual de amostras com a lesão e positivas para Pasteurella multocida (Pm), Mycoplasma hyopneumoniae (Mhyo), Mycoplasma hyorhinis (Mhyr) e Influenza A na lesão pulmonar, Circovírus suíno Tipo 2 (PCV2 ) em linfonodos mediastínicos. 

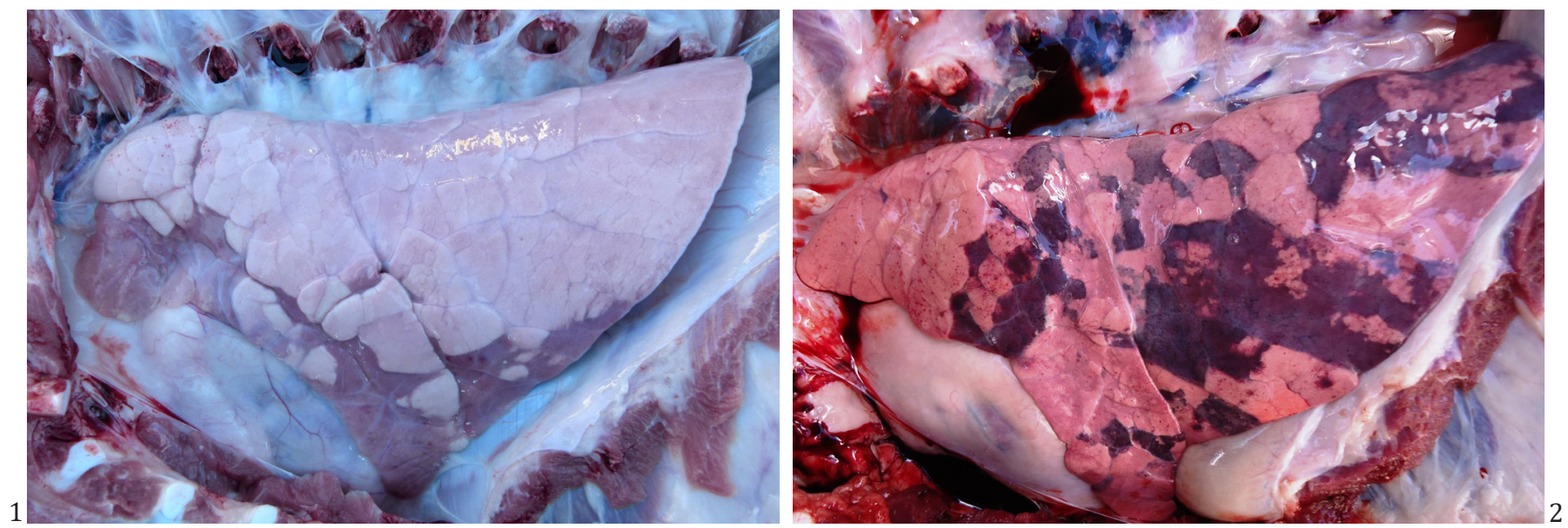

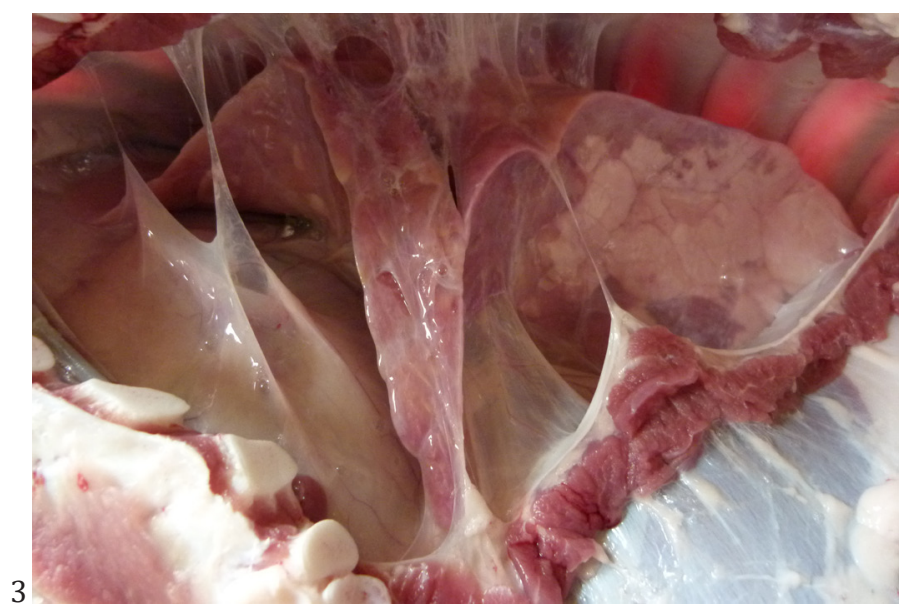

Fig.1. Pulmão suíno apresentando consolidação crânio-ventral.

Fig.3. Pulmão suíno apresentando grandes áreas de consolidação, aderências da pleura à parede costal e ao diafragma e pericárdio com coloração esbranquiçada e aderido à parede costal.

etiológico. Por imuno-histoquímica do tecido pulmonar lesado, $74 \%$ das amostras foram positivas para Mhyo (Fig.7), 2,8\% para o vírus Influenza A e nenhuma amostra foi positiva para PCV2. Em linfonodos mediastínicos 4,2\% foram positivas para PCV2. No isolamento bacteriano das lesões pulmonares, 30 amostras (39\%) não apresentaram crescimento bacteriano e $43(55,8 \%)$ foram positivas para Pasteurella multocida tipo A (PmA). App, Haemophilus parasuis, Arcanobacterium pyogenes e Streptococcus sp foram isolados em uma amostra (1,3\%), de distintos animais. Em dois animais foi isolado PmA em sítio não respiratório, sendo um no pericárdio e peritônio e outro na pleura.

No teste de PCR para Mycoplasma hyorhinis (Mhyr), 19 $(32,2 \%)$ das 59 amostras testadas foram positivas. Ao associar os resultados das amostras com isolamento bacteriano positivo para $P$. multocida com as amostras positivas na imuno-histoquímica para Mhyo, das 65 amostras positivas para Mhyo, $72,3 \%$ foram positivas também para P. multoci$d a$. Por outro lado, das 24 amostras negativas para Mhyo, $54,2 \%$ foram positivas para P. multocida.

Ao analisarmos os resultados bacteriológicos para PmA, IHQ para Mhyo e PCR para Mhyr pelo teste Qui-quadrado,

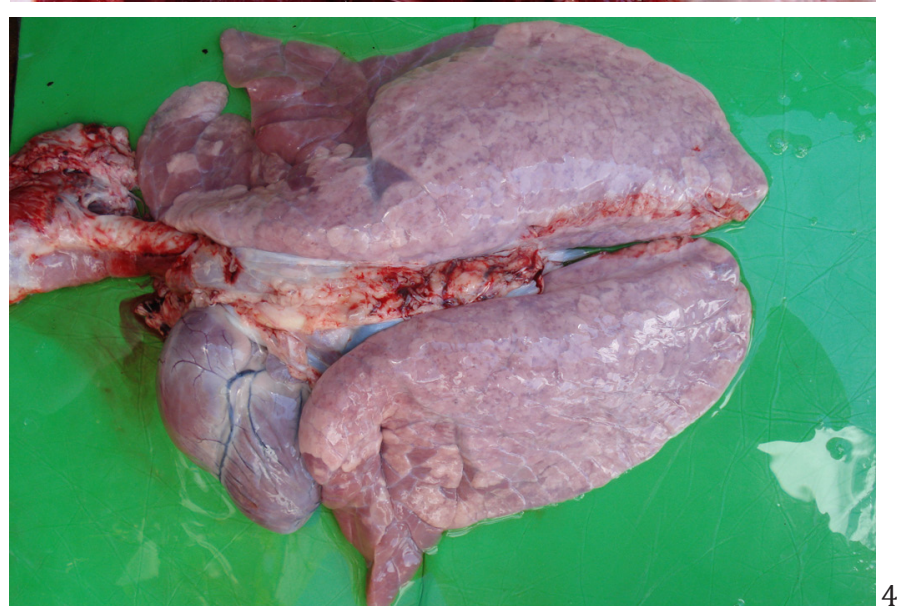

Fig.2. Pulmão suíno apresentando consolidação multifocal.

Fig.4. Pulmão suíno não colabado e apresentando consolidação crânio-ventral.

não houve diferença significativa $(\mathrm{P}>0,05)$ entre os animais oriundos de lotes do sistema de ciclo completo com os oriundos do sistema segregado, assim como também não houve diferença entre os animais de lotes do sistema segregado formado por animais de uma única origem e os oriundos de lotes com mais de uma origem.

Pelo teste $T$ foi observado que as amostras positivas para $P$. multocida apresentaram áreas de consolidação pulmonar mais extensas (média de $38,5 \%, \mathrm{P}<0,05$ ) do que amostras negativas para este agente (média de 26,7\%).

\section{Testes de CIM}

Os percentuais de sensibilidade antimicrobiana das amostras de P. multocida analisadas pelo teste de CIM para os antimicrobianos testados individualmente são apresentados na Figura 8. Nenhum isolado apresentou multirresistência, ou seja, resistência a mais de três classes de antimicrobianos. No entanto, quatro isolados apresentaram resistência a três drogas. Todas as amostras apresentaram sensibilidade a Doxiciclina, Enrofloxacina e Tilmocosina. Apenas quatro $(16,7 \%)$ isolados foram sensíveis a todas as drogas testadas.

Os resultados dos testes de CIM para as associações de antimicrobianos são apresentados no Quadro 6. 0 efeito si- 
Quadro 6. Efeito das associações de antimicrobianos sobre as 24 amostrasde Pasteurella multocida analisadas por CIM (\% das amostras testadas)

\begin{tabular}{lcccc}
\hline Efeito & AMO/TF & AMO/TYL & DOX/TF & LIN/EPT \\
\hline Sinérgico & 29,2 & 8,3 & 37,5 & 83,3 \\
Aditivo & 33,3 & 25,0 & 45,8 & 12,5 \\
Indiferente & 33,3 & 66,7 & 16,7 & 0,0 \\
Antagônico & 4,2 & 0,0 & 0,0 & 4,2
\end{tabular}

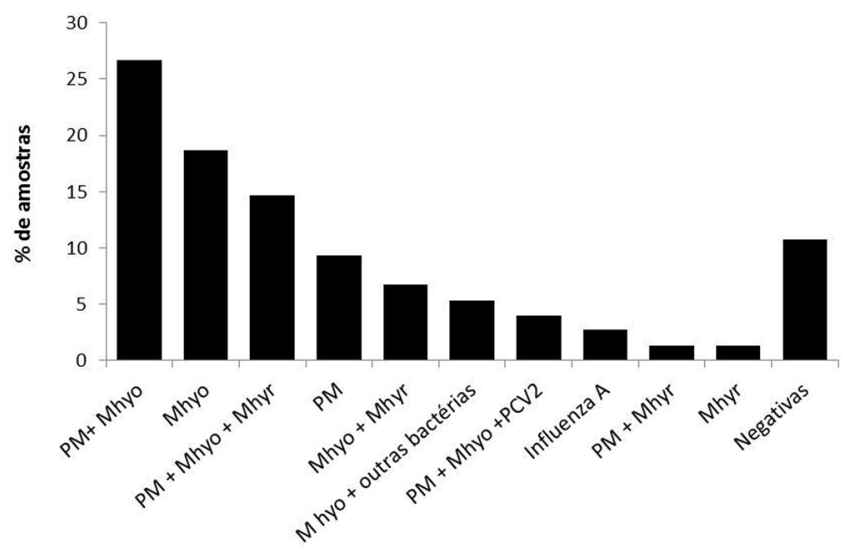

Fig.5. Porcentagem de positividade dos agentes infecciosos identificados isoladamente ou em associações.

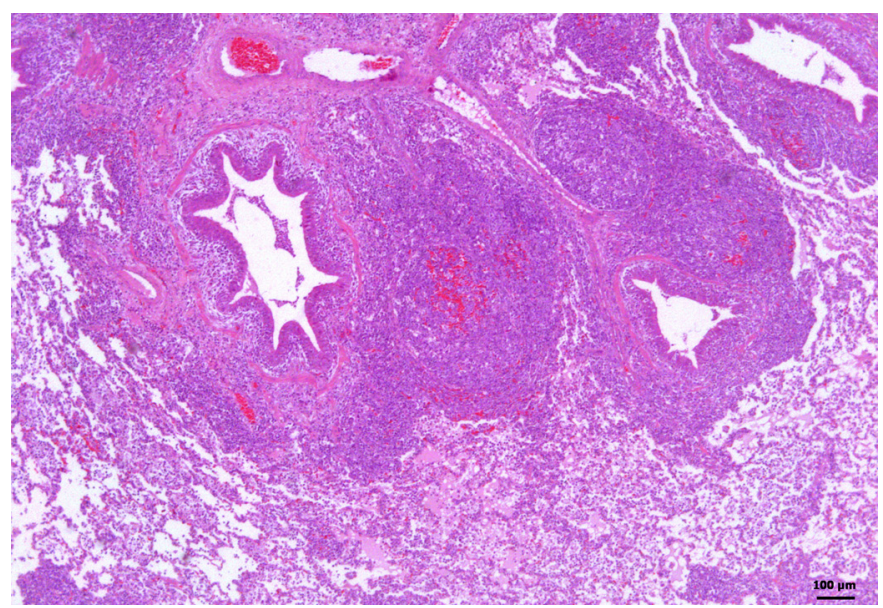

Fig.6. Pulmão com broncopneumonia exsudativa e hiperplasia do tecido linfoide associado aos bronquíolos (BALT). HE, barra $100 \mu \mathrm{m}$.

nérgico foi observado principalmente na associação LIN/ EPT (83,3\%), efeito aditivo na associação DOX/TF $(45,8 \%)$ e o efeito indiferente na associação AMO/TYL $(66,7 \%)$. Já o efeito antagônico não foi significativo em nenhuma das associações.

\section{DISCUSSÃO}

Associações de agentes infecciosos foram encontradas em 44 (58,8\%) amostras (Fig.5). Além disso, foram observadas muitas lesões crônicas sugerindo uma infecção anterior, cujo agente infeccioso, provavelmente, já tenha sido eliminado. Estes resultados evidenciam a alta prevalência das associações de micro-organismos nas doenças respiratórias em suínos de terminação.

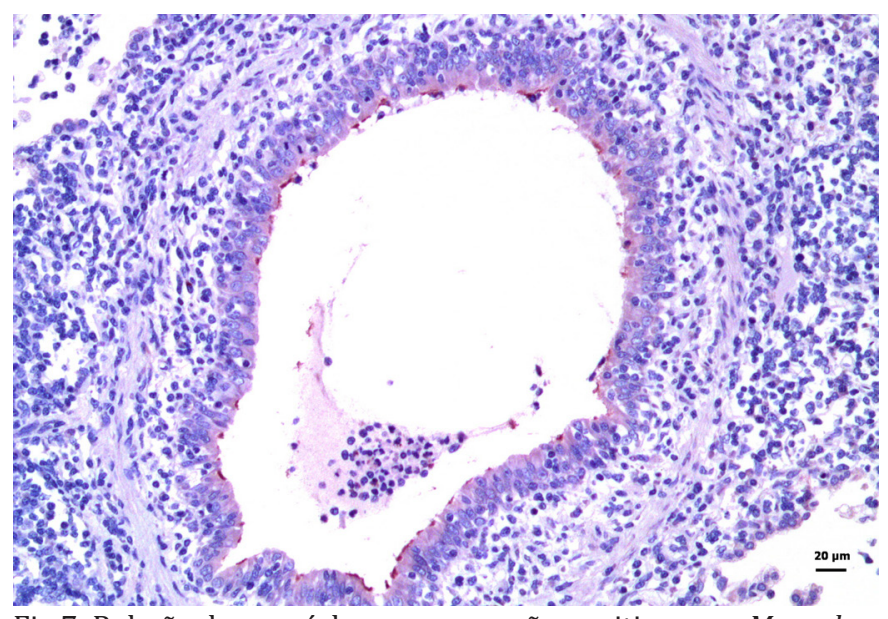

Fig.7. Pulmão, bronquíolo com marcação positiva para Mycoplasma hyopneumoniae nos cílios das células epiteliais (em vermelho). IHQ com anticorpo policlonal anti-proteína p36. Método biotina-estreptavidina-peroxidase, cromógeno 3-Amino-9-Ethylcarbazol (AEC) e contra-coloração com hematoxilina de Mayer, barra $20 \mu \mathrm{m}$.

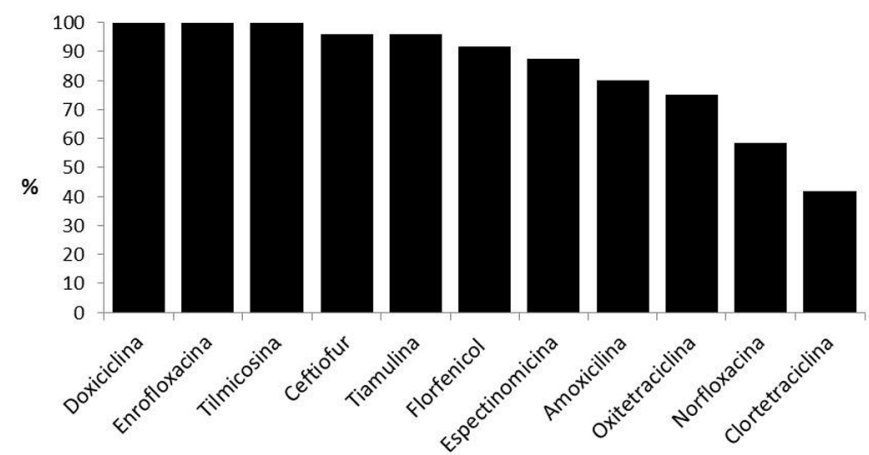

Fig.8. Sensibilidade antimicrobiana de 24 amostras de Pasteurella multocida pela técnica de CIM.

Mycoplasma hyopneumoniae (Mhyo) e Pasteurella multocida tipo $\mathrm{A}(\mathrm{PmA})$ foram os principais agentes infecciosos encontrados. Os tipos de lesões pulmonares mais frequentes, caracterizados macroscopicamente por consolidação pulmonar com localização crânio-ventral e microscopicamente por broncopneumonia supurativa com hiperplasia de BALT, são compatíveis com o envolvimento destes agentes. PmA é uma das principais bactérias relacionadas com pleurites, pericardites e broncopneumonias fibrinosas em suínos (López 2007), lesões também encontradas nos suínos estudados neste trabalho. Estes resultados demonstram a importância destes dois agentes na indução de problemas respiratórios em suínos nos principais Estados produtores do Brasil.

Mhyo é considerado um dos principais agentes primários de pneumonias em suínos em todo o mundo (Thacker 2006, Maes et al. 2008, Hansen et al. 2010). Nos lotes que participaram desta avaliação $87 \%$ tinham sido vacinados para este agente. Os resultados obtidos demonstram que, apesar da vacinação e utilização de antimicrobianos de forma preventiva, medidas utilizadas na maioria das granjas, o controle da infecção não é totalmente eficiente. 0 arranjo 
da cadeia produtiva no Brasil, onde frequentemente ocorrem misturas de leitões de diferentes origens para a formação dos lotes de creche e terminação, fator também evidenciado nesse estudo, favorece a ocorrência de doenças respiratórias (Maes et al. 2008), sendo uma provável causa da dificuldade no controle desta doença. No entanto, neste trabalho não houve diferença $(p>0,05)$ quanto a presença dos principais agentes (PmA, Mhyo e Mhyr) em relação ao tipo do sistema de criação e número de origens dos leitões.

Amostras positivas para Mhyo apresentaram tendência em serem positivas para P. multocida, no entanto, não foi observada associação de infecção entre esses dois agentes $(\mathrm{p}>0,05)$. Este resultado ratifica o papel de P. multocida como o principal agente secundário nas infecções pelo Mhyo em casos de pneumonia enzoótica dos suínos, como reportado por vários autores (Maes et al. 2008, Hansen et al. 2010, Opriessnig et al. 2011). Além disso, neste estudo, quando presente, $P$. multocida aumentou significativamente $(\mathrm{p}<0,05)$ a extensão das lesões de consolidação pulmonar, demonstrando seu importante papel no agravamento de lesões causadas por outros agentes.

Apesar de seu papel predominantemente oportunista, algumas amostras de P. multocida tipo A têm sido relatadas como tendo capacidade em atuar como agente primário em doença respiratória grave e septicemia em suínos (Ono et al. 2003, Cappuccio et al. 2004, Kich et al. 2007, Oliveira Filho 2014), causando poliserosites fibrinosas e broncopneumonias fibrinonecróticas. Neste trabalho, em uma das amostras com severa broncopneumonia fibrinonecrótica e pericardite, $P$. multocida tipo A foi o único agente encontrado, sugerindo seu papel primário neste caso.

Houve associação entre a utilização de vacina autógena para $P$. multocida e o não isolamento deste agente em amostra de lesão pulmonar, o que não ocorreu quando se utilizou vacina comercial, sugerindo uma melhor ação das vacinas autógenas quando comparadas às comerciais. Porém, o número de amostras analisadas foi baixo, o que deve ser considerado na interpretação deste achado. Esse resultado pode ser explicado pela alta variabilidade antigênica entre as amostras de P. multocida isoladas de suínos (Pors, et al., 2011; Bethe et al., 2009).

Sequelas de broncopneumonias fibrinosas estão entre as principais causas de condenações e desvios de carcaças na linha de abate em suínos (Morés, 2006), onde aparecem principalmente como aderências de pleura e nódulos pulmonares. P. multocida e A. pleuropneumoniae são os principais agentes causadores dessas lesões em suínos (Morés 2006, López 2007). Neste estudo, P. multocida foi mais prevalente (8/12) em pulmões com este tipo de lesão do que o A. pleuropneumoniae (1/12), demonstrando sua possível importância como causa destas condenações em suínos na produção brasileira. Salienta-se a dificuldade no diagnóstico destes quadros devido ao estágio crônico com que estas lesões aparecem no abatedouro, especialmente nos casos de pleurite sem pneumonia. Todavia, a participação de amostras de $P$. multocida nas pleurites/pericardites crônicas encontradas nos suínos abatidos deve se melhor investigada. Enfatizando estes aspectos, neste estudo a maioria das lesões de pleura encontradas eram crônicas e, em apenas uma amostra foi possível o isolamento bacteriano da lesão, sendo que o agente isolado foi $P$. multocida tipo A.

A participação do Mhyr nas doenças respiratórias dos suínos ainda não é completamente clara (Palzer et al. 2008). Há relatos de sua importante participação em lesões de pneumonia enzoótica e doença respiratória em geral (Hansen et al. 2010, Lin et al. 2006), assim como alguns autores relacionando-o como agente primário em poliserosites de leitões jovens (Thacker 2006). A prevalência de $32,2 \%$ encontrada neste estudo, nas amostras de lesão pulmonar pela PCR, indica que este agente está difundido nas regiões amostradas, porém não houve correlação da presença do Mhyr com lesões de broncopneumonias e serosites (quadro 5), portanto não é possível inferir sobre sua importância na indução destas lesões.

O Circovírus suíno tipo 2 (PCV2) teve prevalência baixa na IHQ em linfonodo mediastínico e não foi encontrado em lesões pulmonares. Apesar da circovirose normalmente acometer suínos mais jovens do que os analisados, este resultado demonstra que a doença está sob controle na maioria dos rebanhos analisados. Boa parte deste controle está, provavelmente, relacionado com a efetividade das vacinas atualmente utilizadas contra o PCV2.

Actinobacillus pleuropneumoniae também apresentou baixa prevalência neste estudo, diferentemente de outros trabalhos realizados (Morés, 2006). Este resultado indica o baixo desafio do agente nas regiões estudadas, visto que apenas $50 \%$ dos lotes foram vacinados, conforme Quadro 3.

$\mathrm{O}$ vírus Influenza A é outro agente difundido nos rebanhos suínos brasileiros (Morés et al., 2011, Schaefer et al. 2011). A prevalência encontrada nesse trabalho, de 2,8\% no teste de IHQ, é baixa, porém este número pode estar subestimado devido às características do agente, pois o vírus permanece poucos dias nos tecidos após a infecção (Vincent et al. 1997), sendo detectado somente em lesões agudas. Lesões crônicas de pneumonia intersticial (20\%) e bronquite/bronquiolite epitelial proliferativa (8\%), observadas no exame histopatológico, são compatíveis com o quadro microscópico crônico provocado por este vírus (Schaefer et al. 2011).

Outro agente viral muito importante como causa de doença respiratória em países com produção intensiva de suínos é o vírus da síndrome reprodutiva e respiratória dos suínos (PRRS). Este agente não foi pesquisado neste estudo, pois a doença ainda não foi notificada no Brasil (Brasil 2015) e, em estudo sorológico recente, não foi identificada a presença de anticorpos contra esse agente (Ciacci-Zanella et al. 2013).

Úlcera gástrica foi identificada com frequência moderada $(25,4 \%)$ neste estudo. A correlação entre a presença desta lesão com a ocorrência de doença respiratória já foi demonstrada (Straw et al., 1992) e, provavelmente, está relacionada à anorexia e ao estresse induzidos durante o curso das doenças respiratórias.

A utilização de antibióticos de forma preventiva é prática comum na suinocultura intensiva. Com isso é esperado o aparecimento de resistência bacteriana ao longo do tempo 
às principais drogas utilizadas. 0 maior percentual de resistência das amostras de P. multocida tipo A avaliadas frente os produtos NOR, OTC, CTC e AMO, pode estar relacionado à utilização mais frequente destes produtos nas granjas ou ao maior tempo em que estas drogas estão disponíveis no mercado. As tetraciclinas não estão sendo mais utilizadas na maioria dos sistemas produtivos, devida às restrições de países importadores, porém foram muito utilizadas no passado. A TF e o FFN, produtos bastante utilizados atualmente nos programas de medicação para doenças respiratórias por induzirem boa concentração de princípio ativo no pulmão, foram eficientes para mais de $90 \%$ das amostras testadas, demonstrando serem boas alternativas para o controle da pasteurelose pulmonar. Os três antibióticos em que $100 \%$ das amostras foram sensíveis, DOX, ENO e TYL, não têm seu uso muito difundido nas granjas, conforme observado no Quadro 3.

$\mathrm{Na}$ avaliação das associações de antimicrobianos frente a P. multocida A, somente a associação LIN/EPT apresentou elevado percentual de sinergismo $(82,6 \%)$. Porém, se somados os percentuais de sinergismo e adição, temos a LIN/EPT com 95,6\%, a DOX/TF com 81,9\%, a AMO/TF com $61,9 \%$ e somente a AMO/TYL com apenas 33,3\%. Neste caso, é importante lembrar que a EPT não é absorvida quando administrada for via oral. Ainda, merece atenção o fato do percentual de antagonismo ser insignificante para todas as associações testadas, ou seja, embora em alguns casos não ocorra vantagem na utilização dessas associações para controle da $P$. multocida $\mathrm{A}$, também não há prejuízo. Estes dados são importantes, pois, na maioria das vezes, a utilização de associações de antibióticos em programas estratégicos para suínos, objetiva controlar diferentes agentes infecciosos, sem focar especificamente em sinergismo ou adição.

Conclui-se que broncopneumonias e pleurites são as lesões respiratórias mais frequentes nos suínos de terminação de lotes com sinais de doença respiratória. Nestes animais, na maioria das vezes, houve associação do Mhyo com PmA. Outros agentes estavam presentes com menor frequência. Quando PmA esteve presente houve aumento da extensão das lesões pulmonares. Ações mais efetivas para o controle destes dois agentes são necessárias para a redução da prevalência e gravidade dos quadros clínicos respiratórios nas granjas.

Agradecimentos.- À Embrapa pelo financiamento do projeto de pesquisa. À todas as empresas e suas equipes técnicas que permitiram a entrada nas granjas e auxiliaram na colheita de amostras. Aos colaboradores e estagiários da Embrapa Suínos e Aves que auxiliaram na colheita e análises das amostras: Franciana Belaver, Franciele Ianiski, Kelen Ascoli, Caio Zaccaro, Juliana Bassani, Emanuele Cervelin e Gilnei Bruno da Silva.

\section{REFERÊNCIAS}

Bethe A., Wieler L.H., Selbitz H. \& Ewers C. 2009. Genetic diversity of porcine Pasteurella multocida strains from the respiratory tract of healthy and diseased swine. Vet. Microbiol. 139:97-105.

Brasil 2015. Lista de doenças de notificação obrigatória ao serviço veterinário oficial. Sistema de Informação Zoossanitária, Sanidade Animal, Ministério da Agricultura, Pecuária e Abastecimento, Brasília, DF. Disponível em <http://www.agricultura.gov.br/animal/sanidade-animal/ sistema-informacoes-zoosanitarias> Acesso em 9 jun. 2015.
Cappuccio J., Leotta G.A., Vigo G., Moredo F., Wolcott M.J. \& Perfumo C.J. 2004. Phenotypic characterization of Pasteurella multocida strains isolated from pigs with bronco and pleuropneumonia. Proc. 18th International Pig Veterinary Society Congress, Hamburg, Germany, p.205. (Resumo)

Ciacci-Zanella J.R., Morés N., Simon N.L., Oliveira S.R. \& Gava D. 2006. Identificação do circovírus suíno tipo 2 por reação em cadeia da polimerase e por imunoistoquímica em tecidos suínos arquivados desde 1988 no Brasil. [Identification of porcine circovirus type 2 by polymerase chain reaction and immunohistochemistry on archived porcine tissues since 1988 in Brazil]. Ciência Rural 36:1480-1485. <http://www.scielo.br/ scielo.php?script=sci_pdf\&pid=S010384782006000500021\&lng=en\&nrm=iso\&tlng=pt)> (In Portuguese, with English abstract)

Ciacci-Zanella J.R., Gava D., Schaefer R., Klein C.S., Silva V.S. \& Caron L. 2013. No indication of porcine reproductive and respiratory syndrome virus (PRRSV) infection in Brazilian swine herds. Proc. Allen D. Lemann Swine Conference, Saint Paul, USA, p.192. (Resumo)

Clinical and Laboratory Standards Institute 2005. 15 Informational Supplement. CLSI, Wayne. PA. 177p.

Castro L.A., Schuck D., Morés N., Zaha A., Ferreira H.B. \& Driemeier D. 2009. Monospecific polyclonal antibodies for immunodetection of $M y$ coplasma hyopneumoniae in swine pneumonic lungs. Vet. Immunol. Immunopathol. 128:336-337.

Eucast 2000. Determination of antimicrobial susceptibility test breakpoints. European Committee for Antimicrobial Susceptibility Testing), European Society of Clinical Microbiology and Infectious Diseases (E.DEF 2.1, 2000). Clin. Microbiol. Infect. 6:570-572.

Fraile L., Alegre A., López-Jiménez R., Nofrarías M. \& Segalés J. 2010. Risk factors associated with pleuritis and cranio-ventral pulmonary consolidation in slaughter-aged pigs. Vet. J. 184:326-333.

Garcia L., Shore I. \& Henry D. 2010. Clinical Microbiology Procedures Handbook. 3rd ed. ASM, Washington, DC. 540p.

Hansen M.S., Pors S.E., Jensen H.E., Bille-Hansen V., Bisgaard M., Flachs E.M. \& Nielsen O.L. 2010. An investigation of the pathology and pathogens associated with porcine respiratory disease complex in Denmark. J. Comp. Pathol. 143:120-131.

Kich J.D., Mores N., Triques N.J., Nogueira M.G., Locatelli C., Klein C.S. \& Felicio R.P. 2007. Pasteurella multocida Tipo A atuaria como agente primário nos processos pneumônicos dos suínos? Comun. Téc. 469, Embrapa Suínos e Aves, Concórdia <wwWcnpsAembrapAbr/sgc/sgc_publicacoes/publicacao_x8g42b6i.pdf>

Lin J.H., Chen S.P., Yeh K.S. \& Weng C.N. 2006. Mycoplasma hyorhinis in Taiwan: diagnosis and isolation of swine pneumonia pathogen. Vet. Microbiol. 115:111-116.

López A. 2007. Respiratory System, p.463-558. In: McGavin M.D. \& Zachary J.F (Eds), Pathologic Basis of Veterinary Disease. 4th ed. Mosby. St Louis.

Maes D., Segales J., Meyns T., Sibila M., Pieters M. \& Haesebrouck F. 2008. Control of Mycoplasma hyopneumoniae infections in pigs. Vet. Microbiol. 126:297-309.

Morés M.A.Z., Kuchiishi S.S., Ascoli K.R. \& Morés N. 2011. Etiologia de problemas respiratórios em suínos enviados ao CEDISA para diagnóstico no ano de 2010. Anais 15 Congresso Brasileiro de Veterinários Especialistas em Suínos, Fortaleza, CE. CD-ROM. (Resumo)

Morés M.A.Z. 2006. Anatomopatologia e bacteriologia de lesões pulmonares responsáveis por condenações de carcaças em suínos. Dissertação de Mestrado em Ciências Veterinárias, Universidade Federal do Paraná, Curitiba. 91p.

Oliveira Filho J.X. 2014. Estudo da patogenia e desenvolvimento de métodos de diagnóstico da pasteurelose pneumônica em suínos. Tese de Doutorado em Ciências Veterinárias, Universidade Federal do Rio Grande do Sul, Porto Alegre. 124p.

Ono M., Okada M., Namimatsu T., Fujii S., Mukai T. \& Sakano T. 2003. Septicaemia and arthritis in pigs experimentally infected with Pasteurella multocida capsular serotype A. J. Comp. Pathol. 129:251-258.

Opriessnig T., Giménez-Lirola L.G. \& Halbur P.G. 2011. Polymicrobial respiratory disease in pigs. Anim. Health Res. Rev. 12:133-148. 
Palzer A., Ritzmann M., Wolf G. \& Heinritzi K. 2008. Associations between pathogens in healthy pigs and pigs with pneumonia. Vet. Rec. 162:267-271.

Piffer I.A. \& Brito J.R.F. 1991. Descrição de um modelo para avaliação e quantificação de lesões pulmonares de suínos e formulação de um índice para classificação de rebanhos. Comum. Téc. N 23, Embrapa Suínos e Aves, Concórdia.SC.

Pors S.E., Hansen M.S., Christensen H., Jensen H.E., Petersen A. \& Bisgaard M. 2011. Genetic diversity and associated pathology of Pasteurella multocida isolated from porcine pneumonia. Vet. Microbiol. 150:354-361.

Quinn P.J., Markey B.K., Leonard F.C., Fitzpatrick E.S., Fanning S. \& Hartigen P.J. 2011. Pasteurella species, Mannheimia haemolytica and Bibersteinia trehalosi, p.300-308. In: Ibid. (Eds), Veterinary Microbiology and Microbial Disease. 2nd ed. Wiley-Blackwell. Ames, Iowa.

Schaefer R., Zanella J.R.C., Brentano L., Vincent A.L., Ritterbusch G.A., Silveira S., Caron L. \& Mores N. 2011. Isolation and characterization of a pandemic H1N1 inluenza virus in pigs in Brazil. Pesq. Vet. Bras. 31(9): 761-767.
Straw B., Henry S., Nelssen J., Doster A., Moxley R., Rogers D., Webb D. \& Hogg A. 1992. Prevalence of lesions in the pars esophagea of normal and sick pigs. Proc. International Pig Society Congress. Hague, Netherlands, p.386.

Tang X., Zhao Z., Hu J., Wu B., Cai X., He Q. \& Chen H. 2009. Isolation, antimicrobial resistance, and virulence genes of Pasteurella multocida strains from swine in China. J. Clin. Microbiol. 47:951-958.

Stakenborg T., Vicca J., Butaye P., Imberechts H., Peeters J., De Kruif A., Haesebrouck F. \& Maes D. 2006. A multiplex PCR to identify porcine mycoplasmas present in broth cultures. Vet. Res. Commun. 30:239-247.

Thacker E.L. 2006. Mycoplasmal diseases, p.701-717. In: Straw B.E., Zimmerman J.J., D’Allaire S. \& Taylor D.J. (Eds), Diseases of Swine. 9th ed., Blackwell Publishing, Oxford.

Vincent L.L., Janke B.H., Paul P.S. \& Halbur P.G. 1997. A monoclonal-antibody-based immunohistochemical method for the detection of swine influenza virus in formalin-fixed, paraffin-embedded tissues. J. Vet. Diagn. Invest. 9:191-195. 